\title{
Potencial produtivo de híbridos de mamona em diferentes densidades de plantas na segunda safra em ambiente estressante
}

\author{
Yield potential of hybrid castor bean plants in different plant densities in the off season in a \\ stressful environment
}

\section{Brenda Juliana Elias Cruz ${ }^{* 1}$, Danielle Cristina Lancarovici Alves ${ }^{1}$, Rogério Oliveira de Sá ${ }^{2}$, Ronaldo da Silva Viana ${ }^{1}$, Samuel Ferrari ${ }^{1}$}

\author{
${ }^{1}$ Universidade Estadual Paulista, Faculdade de Ciências Agrárias e Tecnológicas, Dracena, SP, Brasil. *Autor para correspondência: \\ brendajuliana55@gmail.com \\ ${ }^{2}$ Instituto Mato-grossense do Algodão, Primavera do Leste, MT, Brasil.
}

Submissão: 05/10/2020 / Aceite: 13/12/2020

\begin{abstract}
RESUMO
A mamona (Ricinus communis L.) tem proporcionado relevância no plano agroindustrial do país pela qualidade do óleo produzido. A obtenção de híbridos adaptados às condições de cultivo em segunda safra e com características apropriadas ao cultivo mecanizado é visado através do melhoramento. Assim sendo, o trabalho teve por objetivo avaliar híbridos precoces de mamona em função de populações de plantas cultivados na região da Nova Alta Paulista em segunda safra. Adotou-se o delineamento experimental em blocos casualizados em esquema fatorial $3 \times 4$, sendo três híbridos de mamona (AGIMA 110204, MIA e TAMAR) e quatro densidades de plantas por metro linear (2, 4, 6 e 8), com quatro repetições por tratamento. No dia 12 de abril de 2017 aconteceu a semeadura na fazenda de pesquisa da UNESP/FCAT - Campus de Dracena. As avaliações de desenvolvimento de plantas e características reprodutivas foram realizadas aos 138 dias após a emergência das plantas (DAE). Altura de plantas, números de racemos por planta, massa de cem grãos e leitura SPAD de clorofila nos tratamentos testados tiveram médias semelhantes. O híbrido TAMAR apresentou a maior altura de inserção do primeiro racemo, e junto com o hibrido MIA tiveram os maiores racemos produzidos. O diâmetro do caule de todos os híbridos apresentou redução linear em função do aumento da população de plantas na linha de semeadura. A produtividade de grãos dos híbridos foi de $1.784 \mathrm{~kg} \mathrm{ha}^{-1}$ (TAMAR), $1.659 \mathrm{~kg} \mathrm{ha}^{-1}$ (AGIMA 110204) e $1.547 \mathrm{~kg} \mathrm{ha}^{-1}$ (MIA).
\end{abstract}

PALAVRAS-CHAVE: Ricinus communis L., produtividade, desenvolvimento vegetativo.

\begin{abstract}
The relevance of the castor bean plant in Brazil's agribusiness plan lies in the quality of the oil it produces. That is why, to improve its quality, there is interest in obtaining hybrid plants adapted to off-season growing conditions and with the appropriate characteristics for mechanized cultivation. This study was conducted to examine the premature growth of hybrid castor bean plants as a function of plant populations cultivated in the off season in the Nova Alta Paulista region of the state of São Paulo. A randomized complete block design with a $3 \times 4$ factorial arrangement, three hybrid castor bean plants (AGIMA 110204, MIA, and TAMAR) and four individuals per linear meter (2, 4, 6, and 8), was adopted, and four replications were performed for each treatment. The seeds were sown on April 12, 2017, at the UNESP/FCAT research farm in Dracena, São Paulo. Assessments on plant development and reproductive traits were made 138 days after emergence (DAE). The plants' height, number of racemes per plant, 100-grain weight, and SPAD chlorophyll reading in the treatments resulted in similar averages. The TAMAR hybrid presented the highest insertion point for the primary raceme and, along with the MIA hybrid, produced the largest racemes. The stem diameter of all the hybrids presented a linear decrease as the plant population increased along the line the seeds were sown. The grain yields of the hybrids were $1,784 \mathrm{~kg} \mathrm{ha}^{-1}$ (TAMAR), 1,659 kg ha ${ }^{-1}$ (AGIMA 110204), and 1,547 $\mathrm{kg} \mathrm{ha}^{-1}$ (MIA).

KEYWORDS: Ricinus communis L., yield, vegetative development.
\end{abstract}




\section{INTRODUÇÃO}

A mamoneira é uma oleaginosa cuja produção está centralizada na Índia e China, produzindo cerca de $93 \%$ da produção mundial (FAOSTAT 2019). O principal produto negociado no mercado internacional é o óleo, de interesse pela indústria ricinoquímica (FERREIRA et al. 2006a). De acordo com CONAB (2019), na safra 2017/2018 foram cultivados 31,8 mil hectares com a cultura, e na safra 2018/2019 a área cultivada foi de 47,9 mil hectares, principalmente nos Estados da Bahia e Mato Grosso, por conta da procura de novas fontes energéticas, opções de cultivo e rotação de culturas em segunda safra.

As cultivares de ciclo longo (180 a 210 dias) são ajustadas para regiões tropicais por apresentarem maior tolerância a estresses e adequadas a produtores com baixa tecnologia. Cultivares de ciclo médio (150 dias) e de ciclo precoce (120 a 130 dias) são adaptadas à colheita mecânica, pelo fato de apresentarem poucos racemos, podendo haver apenas um, sendo assim, são recomendadas para produtores que utilizam alta tecnologia (AZEVEDO et al. 2007).

O melhoramento genético da mamoneira visa produzir cultivares precoces, de porte baixo, maturação uniforme das sementes e alto potencial produtivo, já que a cultura tem provado grande importância no setor agroindustrial do país. Com a finalidade de lapidar o sistema produtivo da cultura, se faz necessário definir uma população satisfatória de plantas com o intuito de determinar o arranjo mais apropriado para alcançar maior produtividade e adaptação à colheita mecanizada.

A consciência do arranjo espacial ideal de plantas para cultivares de mamona, acarreta em tecnologia de produção com baixo custo. $O$ arranjo adequado de plantas da cultura confere ganhos em relação a competitividade de plantas daninhas e em produtividade de grãos (FRANÇA et al. 2013).

Segundo FERREIRA et al. (2006b), a mamoneira ramifica menos quando é submetida ao aumento de densidades populacionais, sendo que cultivares de porte médio podem se comportar como cultivares de porte baixo, emitindo um ou dois racemos por planta, o que proporciona uma maior uniformidade de stand e maturação dos frutos, facilitando posteriormente na colheita mecânica e aumentando o índice de colheita.

A produtividade é uma característica considerada no melhoramento genético da mamoneira a mais trabalhada para lançar híbridos de alto valor para o produtor, pois é uma característica complexa que depende da capacidade de absorção de água, nutrientes e da eficiência de fotossíntese. Os componentes da produtividade são: número de cápsulas por racemos, número de racemos por planta e peso da semente (GONÇALVES et al. 1981, SALUNKHE \& DESAI 1986, LAURETI \& BRIGHAM 1987).

$\mathrm{O}$ instituto Mato-grossense do algodão (IMAmt), depois de anos de pesquisa, desenvolveu a tecnologia de produção de cultivares híbridos para o ambiente do cerrado. Os materiais híbridos alcançados são de ciclo curto, porte baixo e uniformes, que são características favoráveis para a colheita mecanizada. Tem destaque entre as cultivares desenvolvidas, o híbrido simples AGIMA 110204, de tecnologia brasileira, com produtividade superior a $1.500 \mathrm{~kg} \mathrm{ha}^{-1}$, estabilidade de produção, porte anão $(1,70 \mathrm{~m})$, ciclo de cultivo precoce (140 DAE), florescimento precoce (30 DAE) e controle de nematoide.

No Brasil, por meio da Terasol, são comercializadas variedades de mamona de propriedade da Kaiima Bio-Agritech. Com sede em Israel, a Kaiima é uma empresa de tecnologia genética e reprodutiva, que desenvolve plataformas inovadoras melhorando a produtividade de plantas para sistemas agrícolas de larga escala. Um sistema integrado de cultivo de mamona lançado pela Kaiima é o Castor Maxx, que combina sementes híbridas com protocolos evoluídos de crescimento em larga escala, permitindo o crescimento da produção de mamona e do potencial de rendimento de grãos e óleos.

Dessa forma, este trabalho teve como objetivo avaliar híbridos precoces de mamona em função de densidades de plantas cultivados na região da Nova Alta Paulista em segunda safra.

\section{MATERIAL E MÉTODOS}

A pesquisa foi desenvolvido na fazenda de pesquisa da UNESP/Faculdade de Ciências Agrárias e Tecnológicas - Campus de Dracena, SP. De acordo com a classificação climática de Köeppen, o clima na região é do tipo Aw, que se caracteriza pelo clima tropical chuvoso com inverno seco. O município está localizado a uma latitude 21⒉'57" Sul e a uma longitude 5131'58" Oeste, estando a uma altitude de 421 metros, com temperatura média de $22,1 \stackrel{\circ}{ } \mathrm{C}$ e precipitação pluvial média anual de $1.204 \mathrm{~mm}$, como mostra a Figura 1.

Foi adotado o delineamento experimental de blocos ao acaso, num esquema fatorial $3 \times 4$, sendo três híbridos de mamona (AGIMA 110204, MIA e TAMAR) e quatro densidades de plantas (22.222; 44.444; 66.666 e 88.888 plantas ha $^{-1}$ ), com quatro repetições. As parcelas foram constituídas por quatro linhas da cultura da mamona com 6,0 m de comprimento, espaçadas de 0,9 m entre si $\left(21,6 \mathrm{~m}^{2}\right)$. A área útil de cada parcela foi constituída pelas duas linhas centrais, desprezando-se $0,50 \mathrm{~m}$, em ambas as extremidades de 
cada linha.

Em fevereiro de 2017 foi realizada amostragem de solo para a caracterização dos atributos químicos, seguindo a metodologia de análise descrita por RAIJ et al. (2001), que revelou os valores de matéria orgânica de $13 \mathrm{~g} \mathrm{dm}^{-3}, 4,5$ para $\mathrm{pH}\left(\mathrm{CaCl}_{2}\right), 2 \mathrm{mmolc} \mathrm{dm}^{-3}$ para $\mathrm{K}, 4 \mathrm{mmolc} \mathrm{dm}^{-3}$ para $\mathrm{Ca}, 3 \mathrm{mmolc} \mathrm{dm}^{-3}$ para

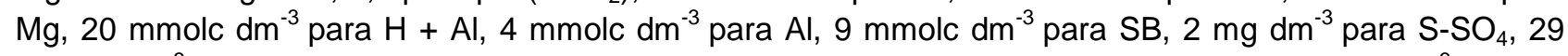
mmolc $\mathrm{dm}^{-3}$ para CTC, $31 \%$ para $\mathrm{V}, 14$ para $\mathrm{Ca} / \mathrm{CTc}, 10 \%$ para $\mathrm{Mg} / \mathrm{CTC}, 31$ para $\mathrm{M}, 0,06 \mathrm{mg} \mathrm{dm}^{-3}$ para $\mathrm{B}$, $0,7 \mathrm{mg} \mathrm{dm}^{-3}$ para $\mathrm{Cu}, 21 \mathrm{mg} \mathrm{dm}^{-3}$ para Fe, $9,2 \mathrm{mg} \mathrm{dm}^{-3}$ para Mn e $0,8 \mathrm{mg} \mathrm{dm}^{-3}$ para $\mathrm{Zn}$.

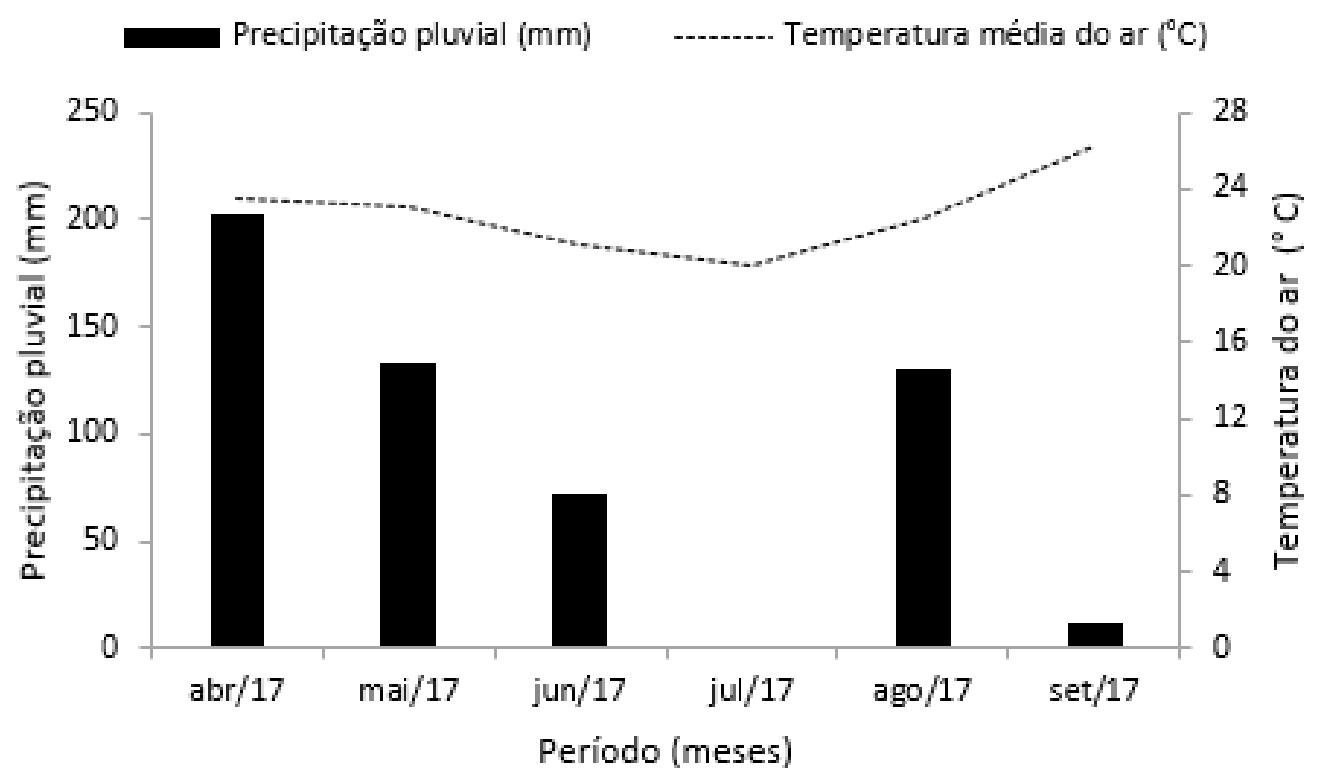

Figura 1. Dados climáticos registrados de temperatura média do $\operatorname{ar}\left({ }^{\circ} \mathrm{C}\right)$ e precipitação pluvial $(\mathrm{mm})$ durante a condução do experimento. Dracena, SP, Brasil, 2019.

Figure 1. Climate data recorded for mean air temperature $\left({ }^{\circ} \mathrm{C}\right)$ and rainfall $(\mathrm{mm})$ during the experiment. Dracena, SP, Brazil, 2019.

O preparo convencional do solo da área experimental para a semeadura da mamoneira foi realizado em março de 2017, por meio de uma operação de aração seguida de duas operações de grade leve. A semeadura manual dos híbridos de mamona foi realizada em 12 de abril de 2017, utilizando-se o dobro de sementes do que a população pretendida nos tratamentos. Utilizou-se na adubação de semeadura $440 \mathrm{~kg}$ ha $^{-1}$ do fertilizante $\mathrm{N}-\mathrm{P}_{2} \mathrm{O}_{5}-\mathrm{K}_{2} \mathrm{O}$ com formulação 04-14-08, calculada com base nas características químicas do solo e de acordo com recomendações de KIIHL \& REGITANO NETO (2014). A emergência das plântulas ocorreu cinco dias após a semeadura e o desbaste das plantas em excesso nas linhas de semeadura foi realizado aos 26 dias após a emergência (DAE), objetivando estabelecer as populações desejadas.

Durante a condução do experimento, devido a períodos com falta de precipitação e as plantas apresentarem ponto de murcha das folhas, foi necessário o emprego de irrigação por meio de aspersores. As irrigações foram feitas sempre com um volume de água de $20 \mathrm{~mm}$ em cada aplicação.

As plantas daninhas foram eliminadas por meio de capina em 19 de maio de 2017. Não foi necessário aplicações de inseticidas ou fungicidas pois não ocorrem pragas e doenças nas plantas dos híbridos de mamoneira.

Houve parcelamento da adubação de cobertura, sendo a primeira $35 \mathrm{DAE}$, aplicando-se $30 \mathrm{~kg} \mathrm{ha}^{-1} \mathrm{de}$ potássio (cloreto de potássio) e $30 \mathrm{~kg} \mathrm{ha}^{-1}$ de nitrogênio (ureia) e a segunda $53 \mathrm{DAE}$, somente com nitrogênio na mesma quantidade (KIIHL \& REGITANO NETO 2014).

As avaliações foram realizadas em 20 plantas da área útil de cada parcela. As leituras SPAD de clorofila foram realizadas período de florescimento de cada híbrido (entre 52 DAE e 64 DAE) utilizando-se um clorofilômetro portátil. As demais avaliações foram realizadas no momento de maturidade fisiológica dos grãos, aos 138 DAE. Altura de plantas mensuradas da superfície do solo até a extremidade superior da planta, com o auxílio de uma régua graduada; diâmetro do caule medido com auxílio de um paquímetro, na altura de $0,10 \mathrm{~m}$ em relação ao solo; altura de inserção do primeiro racemo sendo a distância compreendida desde a superfície do solo até a inserção do primeiro racemo da planta; número de racemos produtivos, por contagem visual; comprimento de racemos pela medida do comprimento de todos os racemos.

A produtividade de grãos foi determinada colhendo-se todos os racemos da área útil de cada parcela, 
sendo na sequência separados os grãos, pesados e estimada a produtividade. A massa de 100 grãos foi obtida por pesagem em balança digital analítica de precisão de $0,01 \mathrm{~g}$ após a colheita.

Os dados obtidos foram submetidos à análise de variância através do teste $\mathrm{F}$ ao nível de significância de $5 \%$ de probabilidade. Em seguida foram submetidos à análise de regressão polinomial e ao teste de Tukey, utilizando-se o software estatístico SISVAR 5.6 (FERREIRA 2011).

\section{RESULTADOS E DISCUSSÃO}

Para todas as cultivares e densidades de plantas utilizadas, a comparação de médias para a altura de plantas, diâmetro de caule, massa de 100 grãos e produtividade de grãos foi apresentada através da Tabela 1. De acordo com os dados analisados não alcançaram diferença significativa as características alturas de plantas, massa de 100 grãos e produtividade de grãos.

Tabela 1. Valores de $\mathrm{p}>\mathrm{F}$ e teste de comparação de médias para altura de plantas, diâmetro do caule, massa de 100 grãos e produtividade de grãos de cultivares de mamona em diferentes populações de plantas. Dracena, SP, 2017.

Table 1. $P$-values $>F$ and comparison of means test for plant height, stem diameter, 100-grain weight, and grain yield of castor bean cultivars in different plant populations. Dracena, SP, 2017.

\begin{tabular}{|c|c|c|c|c|}
\hline Teste F & Altura & $\begin{array}{l}\text { Diâmetro de } \\
\text { caule }\end{array}$ & $\begin{array}{l}\text { Massa de } \\
100 \text { grãos }\end{array}$ & $\begin{array}{l}\text { Produtividade de } \\
\text { grãos }\end{array}$ \\
\hline Cultivares (c) & 0,5659 & 0,4729 & 0,1895 & 0,3572 \\
\hline População (p) & 0,9306 & 0,0448 & 0,8943 & 0,8826 \\
\hline$c^{*} p$ & $\begin{array}{c}0,3201 \\
(\mathrm{~cm}) \\
\end{array}$ & $\begin{array}{c}0,1962 \\
(\mathrm{~mm})\end{array}$ & $\begin{array}{c}0,8487 \\
(\mathrm{~g})\end{array}$ & $\begin{array}{r}0,5629 \\
\left(\mathrm{~kg} \mathrm{ha}^{-1}\right)\end{array}$ \\
\hline AGIMA 110204 & 92,38 & 20,79 & 31,38 & 1658,64 \\
\hline MIA & 95,64 & 19,84 & 28,61 & 1546,62 \\
\hline TAMAR & 100,48 & 20,87 & 30,43 & 1784,04 \\
\hline C.V. \% & 19,21 & 11,02 & 12,09 & 23,81 \\
\hline \multirow[t]{2}{*}{ D.M.S. } & 18,94 & 2,31 & 3,73 & 406,33 \\
\hline & \multicolumn{4}{|c|}{ Regressão Polinomial } \\
\hline 2 & 94,95 & $22,23^{(1)}$ & 30,44 & 1678,51 \\
\hline 4 & 94,07 & 20,75 & 30,06 & 1592,18 \\
\hline 6 & 96,17 & 19,52 & 30,65 & 1738,90 \\
\hline 8 & 99,46 & 19,50 & 29,41 & 1642,83 \\
\hline $\mathrm{p}>\mathrm{F}$ (linear) & 0,576 & 0,016 & 0,646 & 0,974 \\
\hline $\mathrm{p}>\mathrm{F}$ (quadrática) & 0,7332 & 0,348 & 0,722 & 0,970 \\
\hline r2 (linear \%) & 73,08 & 88,53 & 35,09 & 0,69 \\
\hline r2 (quadrática \%) & 99,04 & 99,07 & 55,92 & 0,90 \\
\hline \multicolumn{5}{|c|}{${ }^{(1)} y=22,861-0,471 x$} \\
\hline
\end{tabular}

Médias seguidas pela mesma letra não diferem entre si pelo teste de Tukey a 5\% de significância.

Conforme a classificação de NÓBREGA (2008) plantas com altura entre 0,90 a 1,50 m, são julgadas muito baixas. Desta forma, todas as três cultivares avaliadas são consideradas como muito baixas, afinal a maior média encontrada foi de 100,48 cm para a cultivar TAMAR, já que nas demais cultivares a menor média encontrada foi de 92,38 cm para a cultivar AGIMA 110204 e 95, $64 \mathrm{~cm}$ para a cultivar MIA, desta forma, não havendo, em relação à altura de plantas, diferença mínima significativa. A característica de porte baixo foi pretendida no melhoramento da mamona, em razão de favorecer a realização da colheita mecânica e dos tratos culturais, colaborando a inserção de novas tecnologias no cultivo com ganhos na produtividade de grãos (AMARAL 2003).

Analisando o diâmetro do caule, quando é muito grosso, se torna uma característica agronômica que dificulta a colheita mecanizada, já quando é muito fino, exibe problemas de acamamento (NÓBREGA 2008). Não foi encontrada grande variação para essa característica, sendo as maiores médias de 20,87 cm para a cultivar TAMAR, de 20,79 cm para a cultivar AGIMA 110204 e a menor de 19,84 cm para a cultivar MIA. De 
maneira geral, quanto maior for a altura da planta, maior será o diâmetro do caule (PUTTINI 2014). Deste modo, por serem inferiores a $35 \mathrm{~cm}$, as três cultivares foram classificadas como finos. Plantas com colmos mais finos são interessantes para a realização da colheita mecanizada na cultura da mamoneira (LOPES et al. 2008). Foi verificado diminuição linear do diâmetro do caule em função do aumento da população de plantas.

Com relação a massa de 100 grãos, não houve diferença significativa para população de plantas e variedades. Os dados alcançados foram de 31,38 gramas para a cultivar AGIMA 110204, 30,43 gramas para a cultivar TAMAR e 28,61 gramas para a cultivar MIA.

Não foi constatada diferença significativa para a produtividade de grãos de mamona, ainda que tenha havido grande amplitude de variação $(1.546,62$ a 1.784,04). Contudo devesse ressaltar que todos os híbridos estudados apresentaram média de produtividade de grãos no mínimo 2,5 vezes superior à nacional, que foi de $631 \mathrm{~kg} \mathrm{ha}^{-1}$ na safra de 2017/2018 (CONAB 2019), mostrando assim o potencial produtivo que a cultura tem quando cultivada em segunda safra.

$\mathrm{Na}$ Tabela 2, estão as comparações de médias para altura do primeiro racemo, número de racemos produtivos, comprimento da inserção do primeiro racemo e leitura SPAD de clorofila de cultivares de mamona em diferentes populações de plantas.

Tabela 2. Valores de $\mathrm{p}>\mathrm{F}$ e Teste de comparação de médias para altura do primeiro racemo, número de racemos produtivos, comprimento da inserção do primeiro racemo e teor relativo de clorofila (leitura SPAD) de cultivares de mamona em diferentes populações de plantas. Dracena, SP, 2017.

Table 2. P-values $>F$ and comparison of means test for primary raceme height, number of productive racemes insertion point height of the primary raceme, and relative chlorophyll content (SPAD reading) of castor bean cultivars in different plant populations. Dracena, SP, 2017.

\begin{tabular}{ccccc}
\hline Teste $F$ & Altura de racemo & $\begin{array}{c}\text { Número de } \\
\text { racemo }\end{array}$ & $\begin{array}{c}\text { Comprimento de } \\
\text { racemo }\end{array}$ & SPAD \\
\hline Cultivares $(\mathrm{c})$ & 0,0487 & 0,9911 & 0,0002 & 0,8085 \\
População $(\mathrm{p})$ & 0,1216 & 0,2315 & 0,4283 & 0,4360 \\
$\mathrm{C}^{\star} \mathrm{p}$ & 0,3746 & 0,9054 & 0,7163 & 0,7473 \\
& $(\mathrm{~cm})$ & $\left(\mathrm{n}^{\circ}\right)$ & $(\mathrm{cm})$ & SPAD \\
\hline AGIMA 110204 & $30,55 \mathrm{~b}$ & 2,59 & $34,03 \mathrm{~b}$ & 53,91 \\
MIA & $31,81 \mathrm{~b}$ & 2,60 & $50,33 \mathrm{a}$ & 55,55 \\
TAMAR & $36,89 \mathrm{a}$ & 2,63 & $49,23 \mathrm{a}$ & 54,74 \\
C.V. \% & 21,82 & 29,37 & 19,37 & 11,16 \\
D.M.S. & 5,76 & 0,78 & 8,85 & 6,26 \\
& & Regressão Polinomial & \\
\hline 2 & 30,84 & 3,07 & 47,82 & 52,49 \\
4 & 28,55 & 2,42 & 41,25 & 57,04 \\
6 & 37,89 & 2,54 & 45,60 & 53,87 \\
8 & 35,05 & 2,40 & 43,45 & 55,54 \\
p>F (linear) & 0,096 & 0,104 & 0,504 & 0,514 \\
p>F (quadrática) & 0,923 & 0,329 & 0,452 & 0,486 \\
r2 (linear \%) & 45,94 & 60,38 & 16,06 & 15,22 \\
r2 (quadrática \%) & 46,09 & 81,97 & 36,55 & 32,96 \\
\hline
\end{tabular}

Médias seguidas pela mesma letra não diferem entre si pelo teste de Tukey a $5 \%$ de probabilidade.

Ao explorar a Tabela 2, pode-se atentar que a altura de inserção do racemo primário foi de $30,55 \mathrm{~cm}$ para a cultivar AGIMA $110204,31,81 \mathrm{~cm}$ para a cultivar MIA e $36,89 \mathrm{~cm}$ para a cultivar TAMAR. Os materiais mostraram aptidão para colheita mecanizada se tratando do valor das médias de altura de inserção do racemo primário das três cultivares. Segundo KIIHLL (2006) quando a planta apresenta abaixo de $60 \mathrm{~cm}$ de altura, a altura da inserção do primeiro racemo é classificada como muito baixa. Quando menor altura de inserção as cultivares estudadas apresentem, mais importante, visto que está diretamente 
relacionado à adaptação para colheita mecanizada.

Segundo SEVERINO et al. (2006) é um parâmetro ligado à precocidade da planta é a altura de inserção do racemo primário, sendo assim, a planta que emite o primeiro racemo em menor altura é julgada como a mais precoce. Observando a cultivar TAMAR $(36,89 \mathrm{~cm})$, pode-se constatar, em relação a esta característica, diferença significativa, pois se comparada com as outras cultivares AGIMA 110204 (30,55 $\mathrm{cm}$ ), que foi a mais precoce com menor altura de inserção do racemo primário, seguida da cultivar MIA ( 31,8 $\mathrm{cm}$ ), a primeira apresentou uma maior altura da inserção do racemo quando comparada com as outras cultivares AGIMA 110204.

Não houve influência pelos sistemas de plantio espalhamento ou cultivares e não apresentou diferença mínima significativa se tratando do número de frutos/racemos. Em respeito ao espaçamento de 2 plantas por metro, percebe-se um modesto acréscimo no número de racemos na mamona, de 3,07 . De acordo com GONDIM et al. (2004), com a redução do espaçamento entre as plantas, o número de racemos tende a diminuir, no entanto, essa diminuição é corrigida pelo maior número de plantas em uma mesma área.

A cultivar AGIMA 110204 apresentou menor comprimento do racemo se comparada com as outras cultivares tendo como média $34,03 \mathrm{~cm}$, enquanto as cultivares TAMAR e MIA atingiram, respectivamente, $49,23 \mathrm{~cm}$ e $50,33 \mathrm{~cm}$.

Com relação ao teor relativo de clorofila (leitura SPAD), o qual foi determinado mediante leituras com clorofilômetro, para todas as cultivares analisadas, não houve interação na comparação de médias. A concentração de $\mathrm{N}$ na planta e, também, a produtividade, correlaciona-se com o teor de clorofila nas folhas da mamona (SILVA et al. 2012).

\section{CONCLUSÃO}

Altura de plantas, números de racemos por planta, massa de 100 grãos e leitura SPAD de clorofila dos híbridos AGIMA 110204, MIA e TAMAR em diferentes populações de plantas tiveram médias semelhantes.

O híbrido TAMAR apresentou a maior altura de inserção do primeiro racemo, e junto com o híbrido MIA tiveram os maiores racemos produzidos.

O diâmetro do caule de todos os híbridos apresentou redução linear em função do aumento da população de plantas na linha de semeadura.

A produtividade de grãos dos híbridos foi de $1.784 \mathrm{~kg} \mathrm{ha}^{-1}$ (TAMAR), $1.659 \mathrm{~kg} \mathrm{ha}^{-1}$ (AGIMA 110204) e $1.547 \mathrm{~kg} \mathrm{ha}^{-1}(\mathrm{MIA})$.

\section{AGRADECIMENTOS}

Ao Instituto Mato-grossense do Algodão (IMAmt) pela doação das sementes dos híbridos de mamona.

\section{REFERÊNCIAS}

AMARAL JGC. 2003. Variabilidade genética para características agronômicas entre progênies autofecundadas de mamona (Ricinus communis L.) cv. AL Guarany 2002. Tese (Doutorado em Agronomia/Agricultura). Botucatu: UNESP. $59 p$.

AZEVEDO DMP et al. 2007. Manejo cultural. In: AZEVEDO DMP \& LIMA EF. O agronegócio da mamona no Brasil. Campina Grande: Embrapa Algodão. p.223-253.

CONAB. 2019. Acompanhamento da safra brasileira de grãos. Safra 2018/19. Sexto levantamento. Brasília: CONAB. 149 .

FAOSTAT. 2019. Global Food and Agriculture Statistics of FAO. Disponível em: faostat3.fao.org/home/E. A. Acesso em: 25 mar. 2019.

FERREIRA DF. 2011. SISVAR: a computer statistical analysis system. Ciência e Agrotecnologia 35: 1039-1042.

FERREIRA GB et al. 2006a. Variação do crescimento vegetativo e produtivo de alguns genótipos de mamona em diferentes populações de cultivo. In: II Congresso brasileiro da mamona. Anais... Campina Grande: Embrapa Algodão. CD-ROM.

FERREIRA GB et al. 2006b. Produtividade da mamona híbrida savana em diversas populações de plantio no sudoeste da Bahia. In: Il Congresso brasileiro de mamona. Anais... Campina Grande: Embrapa Algodão. CD-ROM.

FRANÇA GR et al. 2013. Comportamento de cultivares de mamona (Ricinus communis) sob diferentes densidades populacionais, no estado do Tocantins. Revista de Ciências Agrárias 36: 317-323.

GONDIM TMS. et al. 2004. Adensamento da mamoneira sob irrigação em Barbalha, CE. In: I Congresso brasileiro de mamona. Anais... Campina Grande: Embrapa Algodão. CD-ROM.

GONÇALVES NP et al. 1981. Cultivares de mamona. Informe Agropecuário 7: 31-33. 
KIIHL TAM \& REGITANO NETO A. 2014. Mamona. In: AGUIAR AT et al. (Eds). Instruções agrícolas para as principais culturas econômicas. Campinas: Instituto Agronômico. p.39-40. (Boletim Técnico 200).

KIIHL TAM. 2006. Obtenção e avaliação preliminar de novos híbridos de mamona (Ricinus communis L.). Tese (Doutorado em Agronomia/Agricultura). Botucatu: UNESP. 52p.

LAURETI D \& BRIGHAM RD. 1987. Genetica e miglioramento del ricino. In: Ministero dell'Agricoltura e Foreste. 2.ed. II Ricino- obiettivi, Strategie e ricerca. p.11-22.

LOPES FFM et al. 2008. Crescimento inicial de genótipos de mamoneira com sementes submetidas ao envelhecimento acelerado. Revista Brasileira de Oleaginosas e Fibrosas 12: 69-79.

NÓBREGA MBM. 2008. Avaliação de genótipos de mamona (Ricinus communis L.) em cruzamentos dialélicos parciais. Tese (Doutorado em Agronomia/Genética e Melhoramento de Plantas). Piracicaba: USP. 77p.

PUTTINI FDA. 2014. Caracterização química e agromorfológica de genótipos de mamona (Ricinus communis L.). Dissertação (Mestrado em Agricultura Tropical e Subtropical). Campinas. Instituto agronômico. 92p.

SALUNKHE DK \& DESAI BB. 1986. Postharvest biotechnology of oilseeds. Boca Raton: CRC Press. 264p.

RAIJ B van et al. 2001. Análise química para avaliação da fertilidade de solos tropicais. Campinas: Instituto Agronômico. $285 p$.

SILVA MAG et al. 2012. Ammonium sulphate on maize crops under no tillage. Bragantia 71: 90-97. 